\title{
On the Design of Cultural Creative Products Under the Influence of Manchu Native Culture Take Fengning Manchu Autonomous County, Chengde City, Hebei Province as an Example
}

\author{
Yang $\mathrm{Cui}^{1 *}$
}

${ }^{1}$ School of Art, Jiangxi University of Finance and Economics

*YangCui.1767164148@qq.com

\begin{abstract}
With the development of contemporary society, globalization is the general trend. Globalization has brought us a lot of convenience, not only to improve the living standard of the people and the understanding of the life and culture of the world, but also to bring opportunities for design. From the introduction to go out is not only the great development of global trade, the development of China's design is also growing. However, under this environment, the freshness of local culture in many regions will become weaker and weaker with the development of society, and local culture will gradually blend into the scope of internationalization. Taking Fengning Manchu Autonomous County, Chengde City, Hebei Province as an example, this paper discusses the influence of the continuous integration and development of the native culture of Manchu on the local cultural creative products. Through the preliminary research, the known cultural and creative products are summarized. Fengning Manchu Autonomous County of Chengde City, Hebei Province has a strong local cultural color and a strong Manchu intangible cultural heritage resources, which preliminary illustrates the method and perspective of applying local culture to the design of cultural creative products. Promote the development and practical use of Manchu cultural creative products.
\end{abstract}

Keywords: Native culture, The Manchu, Cultural and creative products

\section{OVERVIEW OF LOCAL CULTURE OF FENGNING MANCHU AUTONOMOUS COUNTY}

Manchu nationality plays an important role in the history of Chinese nation and is an indispensable and important nation in the history of Chinese nation. According to the statistics of historical data in 1934, the Manchu population accounted for $52.22 \%$ of the total population of Fengning to that time, and there were 117,576 people in Fengning County. But 15 years later the Manchu population in Fengning County had dwindled to 18,713 . The main reason is that many Manchu compatriots were forced to change their ethnic identity or hide their ethnic identity for personal safety due to the oppressive policy of the supreme ruler at that time. After the reform and opening up, the new ethnic policy was implemented, and a large number of Manchu people recovered their national identity. The population of Manchu in the county was 170683, accounting for
$48.65 \%$ of the total population. The Manchu population is spread throughout all parts of the county.

Under the influence of national culture has also got the local culture heritage and development of manchu intangible cultural heritage of many, was born, for example FengNing full paper-cut art in 2018 was rated as state-level non-material cultural heritage, selected the first batch of national cultural heritages, and at the same time in the Chinese intangible cultural heritage in digital museum. Fengning Manchu's zhaozi will be included in the first batch of national intangible cultural heritage projects. It also includes the Announcement on the List of Recommended Projects of the Fourth Batch of Representative Projects of National Intangible Cultural Heritage published on the website of the General Office of the Ministry of Culture, including the Tengshi cloth pasting paintings of Fengning folk. In addition, bark painting, porcelain carving painting and other crafts, yellow flag dance, butterfly dance, Shaman dance and 
many other excellent culture are the important content of the native culture of Fengning Manchu.

\section{A BRIEF ANALYSIS ON THE DIVERSITY OF NATIVE CULTURE IN FENGNING MANCHU AUTONOMOUS COUNTY}

\subsection{Ethnic Culture of Manchu Autonomous County}

Fengning Manchu Autonomous County is a multiethnic gathering place with a total population of 357,000. The main ethnic group is Manchu, and there are 13 ethnic minorities such as Mongolian, Hui and Han, accounting for $77.2 \%$ of the total population, among which the majority of the population is Manchu, accounting for $68.5 \%$. After Fengning Manchu Autonomous County was formally established, Fengning Manchu native culture with strong Manchu cultural characteristics developed rapidly and enriched the cultural content of ethnic minorities in China. Fengning Manchu Autonomous County is the name of Emperor Qianlong royal grant for "Fengfu Kangning" referred to as Fengning, Fengning Manchu Autonomous County was formally established after the approval of the State Council in 1986, and officially listed in 1987.

Greatly in recent years, with national characteristics of native culture inheritance and protection, tengs cloth paste painting, FengNing manchu paper-cut, ChaoZi, flower yangko, paying wu will these colorful manchu culture forms such as are injected into the national spirit in the heart of the manchu skill inheritance and entrenched, become FengNing manchu autonomous county native culture treasure.

\subsection{Fengning County regional culture}

Engning Manchu Autonomous County is a county under the jurisdiction of Chengde City, Hebei Province, located in the north west of Chengde City. Huairou District of Beijing is in the south, and Zhenglan Banner and Duolun County of Inner Mongolia Province are in the north. Chengde Weichang Manchu Mongol Autonomous County in the east and Zhangjiakou in the west. Fengning Manchu Autonomous County is a multiethnic area. It has been a gathering place of Manchu, Mongolian and other ethnic groups since ancient times. It is an important hub connecting Beijing and Inner Mongolia, and is also one of the counties around Beijing and Tianjin. The total area has 8765 square kilometers, is located in the Yanshan Mountains and Inner Mongolia plateau belt, lush vegetation, Bashang plateau area day highland wide. From this regional characteristics of the birth of many because of the environment and climate of the regional culture. Fengning County mountain more, rich vegetation more scenic spots such as scenic Bashang grassland, also known as the first big prairie in the north of Beijing, thousands of pine dam forest park, Fengning Bashang birch forest, willow ditch natural scenic area and other natural landscape, as well as the injection of strong national characteristics of the horn mountain scenic area, big Khan Palace scenic area. These scenic spots, whether natural scenic spots or developed through the long river of history, are all in the regional characteristics of Fengning Manchu Autonomous County and have strong ethnic characteristics. They not only develop the local tourism industry, but also are the disseminators of Manchu culture.

\section{FENGNING MANCHU CULTURAL CREATIVE PRODUCT DESIGN DEVELOPMENT STATUS}

\subsection{The origin of China's cultural creative product design}

China's cultural creative products have a long history, but so far there is no systematic summary and summary. In the Bronze Ware Period, there appeared works of art with decorative patterns, which were the earliest cultural and creative products in China and the rudiments and ancestors of contemporary cultural and creative products. These works of art had the cultural connotation, folk customs and religious beliefs of that time, and were the embodiment of a nation's spirit and material.Display equations should be flush left and numbered consecutively, with equation numbers in parentheses and flush right. First, use the equation editor to create the equation. Then, select the equation, and set the "Equation" Style. Press the tab key and type the equation number in parentheses.

In today's society, local culture is integrated into the scope of internationalization, and more new design trends are also affecting the development of cultural creative products. Our country has been vigorously advocating cultural self-improvement and cultural confidence, cultural creative products with national characteristics are welcomed by contemporary people. Cultural creative product design of local culture has also become a hot topic of The Times. For example, many cultural and creative products with regional and national characteristics such as the cultural and creative products series of the Palace Museum and the cultural and creative products series of the Suzhou Museum have emerged one after another, which play a good role as models and fully display the design status quo of China's cultural and creative products in the emerging stage. 


\subsection{The origin of China's cultural creative product design}

Under the support of national policies, Hebei Province has established a cultural and tourism industry association. Chengde City is also vigorously promoting the development of cultural and creative products, and regularly holds cultural and creative product competitions and other projects. Fengning Manchu Autonomous County has explored a new mode of "intangible cultural heritage + poverty alleviation". It makes use of Fengning's rich intangible cultural heritage and various resources, such as cloth painting, paper cutting, traditional wood making and iron weaving skills, to organize the local poor residents to learn the local ethnic culture and traditional skills, and help the poor households out of poverty. For this reason, Wudaoying Village, Wudaoying Township, Fengning County, established an Intangible Cultural Heritage Paper-cut Poverty Reduction and Employment Workshop for the poor villagers in the village to join in the inheritance of Manchu native culture and get rid of poverty as soon as possible to the path of Intangible Cultural Heritage.

Under such a background, the development of cultural and creative products has become an urgent situation. In the process of cultural creative product creation, the addition of excellent local cultural elements of Manchu can not only make the local culture be recreated in modern design and reflect a new situation, but also make the local culture of Fengning Manchu Autonomous County get effective publicity effect through the Internet, new media and other means.

There are various kinds of modern cultural and creative products, and many cultural and creative products can be created by using one form of elements, which can be sold through various sales channels again to promote the prosperity of the local economy.

\section{EXPLORE THE DESIGN METHODS OF CULTURAL CREATIVE PRODUCTS COMBINING WITH THE NATIVE CULTURE OF MANCHU}

\subsection{Combining Manchu paper-cutting skills, Teng cloth paste painting, Zhuzizhui and other intangible cultural heritage}

Intangible cultural heritage is an important manifestation of the achievements of a nation's history and civilization. How to innovate the intangible cultural heritage is the key point of inheriting the intangible cultural heritage. Through the new means of cultural creative product design, it can radiate new vitality.

Fengning Manchu Autonomous County representative of the intangible cultural heritage of
Fengning Manchu paper-cutting skills, Teng cloth paste painting, Zhuozihui three kinds. At present, cultural creative products are becoming more and more homogenized and lack of local characteristics. Combining these three kinds of intangible cultural heritage to create products with regional characteristics and achievements of Manchu culture and civilization is a vigorous form of innovation. The abstract national patterns will be transformed into concrete cultural and creative products. Through the creative design of intangible cultural heritage, visitors can deeply feel the minority culture of Fengning Manchu Autonomous County.

For example FengNing manchu autonomous county township five camp child carried out "intangible + poverty alleviation" paper-cut employment after the workshop, the blind date after repeated practice, mastered the art of paper-cut art and the essence, become the FengNing manchu paper-cut art heritage, and the corresponding developed on paper-cut series of manchu culture creative products, the first batch of manchu paper-cut culture creative products.

\subsection{Fengning Manchu Autonomous County combined with economic development}

According to 2013 statistics, the gross regional product of Fengning Manchu Autonomous County is 8.71 billion yuan, an increase of $8.6 \%$ compared with 2012. On December 30, 2015, Zhangcheng Expressway was officially opened to traffic. Zhangcheng Expressway is an important part of the Great Outer Ring Road with a total length of 367 kilometers. Fengning Manchu Autonomous County is the only way of Zhangcheng Expressway, which promotes the economic development along the line.

Although Fengning Manchu Autonomous County is accelerating economic transformation, the main economic indicators have been implemented and developed rapidly. But FengNing manchu autonomous county belongs to the state, provincial, depth of counties in countryside, the main population of farmers, so in the culture of creative product design to consider the local main consumer actual consumption level and way of life, as well as the products actual cost too much, can be divided into different levels of consumption level, design a practical and inexpensive products, Let the people enhance the sense of identity and belonging of their own nation, and enjoy it.

\subsection{Incorporating specific time nodes}

Cultural tourism industry is the strategic support industry of Fengning Manchu Autonomous County. With the vigorous implementation of tourism, it also drives the rapid development of cultural and creative industry. It is a good opportunity for cultural and 
creative industry and tourism to integrate and promote each other, which can continuously improve the attraction of important scenic spots.

Taking Fengning No.1 Grassland in the north of Beijing as an example, the No.1 Grassland in the north of Beijing is the main tourist season and summer resort in summer, where the average temperature is 17.4 degrees Celsius and the scenery is pleasant. Therefore, to launch cultural and creative products with Manchu characteristics of Fengning Manchu Autonomous County is to design timely and seasonal products according to specific time nodes. At the same time, the number of tourists in summer is increasing, and the production of cultural and creative products should be intensified to promote the development of tourism and the prosperity of the cultural and creative industry, so as to achieve the goal of common development.

\section{CONCLUSION}

Manchu local culture produced many excellent intangible cultural heritage, a culture with local characteristics and national native culture creative product I want to be meaningful, you first need to have the common features of our nation, thus forming a distinctive brand, the second is the unique feeling to consumers, this is the purpose of the design is more important characteristics of the manchu culture is different from other nations. The design of Manchu cultural and creative products will fully reflect the local culture of Fengning Manchu Autonomous County, and more clearly illustrate the unique design of cultural and creative products under the influence of the local culture of Fengning Manchu Autonomous County.

\section{REFERENCES}

[1] Han, M. (2011)Analysis and protection of historical environment landscape of northern Manchu people. Northeast Normal University, ChangChun.

[2] liang, Y. (2010) Research on the Landscape Design Method of Urban Portal Road Integrating Local Cultural Concept.Modern gardening, 7: $75-76$.

[3] Wu, P. (2006)Research on the Development of Ethnic Relations in Fengning Manchu Autonomous County, Hebei Province.Minzu University of China, BeiJing.

[4] Zhu, JJ. (2019) On the importance of noumenal cultural symbols in landscape design. Culture and Design, 9: 50-55. 